EESTI NSV TEADUSTE AKADEEMIA TOIMETISED. 20. KÖIDE KEEMIA * GEOLOOGIA. 1971, NR. 2

ИЗВЕСТИЯ АКАДЕМИИ НАУК ЭСТОНСКОИ ССР. ТОМ 20 Химия * ГЕОЛОГия. 1971, № 2

УдДК 624.131.6?

Э. ГРНКЕВИЧ

\title{
ОСНОВНЫЕ ЗАВИСИМОСТИ ДЛЯ РАСЧЕТА ПОТЕРЬ НАПОРА И ВХОДНЫХ СКОРОСТЕЙ В ПРОИЗВОЛЬНОМ ИНТЕРВАЛЕ ФИЛЬТРА
}

\author{
E. GRIKEVITSS. POHILISED SOLTUVUSED PINGE LANGEMISTE JA SISENDKIIRUSTE \\ ARVUTAMISEKS FILTRI SUVALISES INTERVALLIS
}

E. GRIKEVICH. ON FUNDAMENTAL EQUATIONS FOR THE CALCULATION OF PRESSURE LOSSES AND INITIAL SPEEDS IN THE RANDOM INTERVAL OF A FILTER

В связи с широким применением геофизических методов при решенни гидрогеологических задач (Гринбаум, 1965; Материалы.., 1967) определенный интерес представляет изучение закономерностей истечения жидкости через заданный интервал фильтра. Знание потерь напора и скоростей движения жидкости у стенки скважины и в ее стволе позволиг более достоверно оценивать фильтрационные свойства вскрытой толщи.

Для расчета потерь напора и входных скоростей предлагаются завнсимости, которые учитывают влияние гидравлического сопротивления скважины на приток жидкости.

Согласно нашим работам (Грикевич, 1970; Грикевич, Руселис, 1970) формула для определения расхода жидкости в заданном сечении ! имеет вид

$$
Q_{l}=\frac{Q \operatorname{sh} c t+Q_{0} \operatorname{sh}(c T-c t)}{\operatorname{sh} c t}
$$

Здесь $Q_{0}$ и $Q$ - расходы жидкости в сечениях $l=0$ и $l=L ; c-$ параметр, равный $\frac{4 \sqrt{2}}{D}$, где $D-$ внутренний диаметр фильтра; $t$ и $T$ - интегральные характеристики, соответственно равные $\mu \eta_{0-l} \cdot l$ и $\mu \eta_{0-L} \cdot L$, где $\mu \eta-$ коэффициент, учитывающий эффект наложения частиц породы на приемную поверхность фильтра, а индексы при нем говорят о том, что это есть средние величины для рассматриваемого отрезка или заданного интервала фильтра соответственно.

Приращение расхода жидкости в элементарном объеме фильтра равно

$$
d Q_{l}=\pi D \sqrt{2 g \Delta h_{l}} d t
$$

где $g-$ ускорение силы тяжести; $\Delta h_{l}-$ разность между пьезометрическими уровнями снаружи и внутри фильтра (снижение напора) в сечении $l$.

Дифференцируя уравнение (1) по $t$, имеем

$$
d Q_{l}=\frac{c}{\operatorname{sh} c T}\left[Q \operatorname{ch} c t-Q_{0} \operatorname{ch}(c T-c t)\right] d t
$$


Приравнивая выражения (2) и (3), получнм

$$
\Delta h_{l}=\frac{1}{g W^{2}} \frac{\left[Q \operatorname{ch} c t-Q_{0} \operatorname{ch}(c T-c t)\right]^{2}}{\operatorname{sh}^{2} c T},
$$

где $W$ - площадь поперечного сечения фильтра.

По формуле (4) при известных исходных данных вычисление величин снижения напора производится независимо от особенностей притока жидкости в скважину вне заданного интервала. Начальное и конечное сечение интервала $\left(l_{0}\right.$ и $\left.L\right)$ могут быть выбраны произвольно.

На основании выражений (1) и (4) получим формулы для определения скорости входа частиц жидкости в фильтр и средней скорости потока внутри фильтра соответственно

$$
\begin{gathered}
u_{l}=\frac{\sqrt{2} \mu}{\operatorname{sh} c T}\left[v \operatorname{ch} c t-v_{0} \operatorname{ch}(c T-c t)\right], \\
v_{l}=\frac{v \operatorname{sh} c t+v_{0} \operatorname{sh}(c T-c t)}{\operatorname{sh} c T} .
\end{gathered}
$$

Отсюда соотношение между скоростями выразится следующим образом:

$$
u_{l}=\sqrt{2} \mu v_{l} \frac{v \operatorname{ch} c t-v_{0} \operatorname{ch}(c T-c t)}{v \operatorname{sh} c t+v_{0} \operatorname{sh}(c T-c t)}
$$

Для конца интервала $(l=L)$, основные формулы примут вид

$$
\begin{gathered}
\Delta h_{L}=\frac{1}{g W^{2}} \frac{\left[Q \operatorname{ch} c T-Q_{0}\right]^{2}}{\operatorname{sh}^{2} c T}, \\
u_{L}=\sqrt{2 \mu} \mu\left(v \operatorname{cth} c T-\frac{v_{0}}{\operatorname{sh} c l}\right) .
\end{gathered}
$$

\section{ЛИТЕРАТУ РА}

Грнн 6 а ум И. И. 1965. Геофизические методы определения фильтрацнонных свойств горных пород. М.

Материалы семинара' по применению геофизических и математических методов при гидрогеологических и инженерно-геологических исследованиях. 1967. Темат. сб. ВСЕГИНГЕО, вЫп. 5. М.

Г рике ви ч Э. А. 1970. Гидравлические сопротивления и входные скорости фильтра с неравномерной перфорацией. Сб. тр. Рижск. политехн. ин-та. Водоснабжение и канализация. Рига.

Грикевич Э. А., Р уселис А. А. 1970. Экспериментальное исследование гидравлики фильтров с переменной перфорацией. Сб. тр. Рижск. политехн. ин-та. Водоснабжение и канализация. Рига. 